Article

\title{
Modelling the Mineralization of Formaldehyde by Treatment with Nitric Acid
}

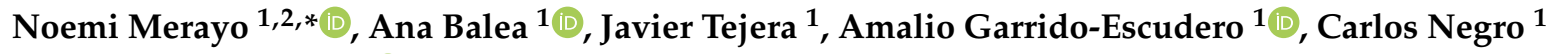 \\ and Angeles Blanco 1,*(D) \\ 1 Department of Chemical Engineering and Materials, Universidad Complutense de Madrid, \\ Av. Complutense s/n, 28040 Madrid, Spain; anabalea@ucm.es (A.B.); jttejo@ucm.es (J.T.); \\ amgarrid@ucm.es (A.G.-E.); cnegro@ucm.es (C.N.) \\ 2 Department of Mechanical, Chemical and Industrial Design Engineering, ETSIDI, Universidad Politécnica \\ de Madrid, Ronda de Valencia 3, 28012 Madrid, Spain \\ * Correspondence: n.merayo@upm.es (N.M.); ablanco@ucm.es (A.B.); Tel.: +34-91-394-4247 (A.B.)
}

Received: 8 May 2020; Accepted: 28 May 2020; Published: 30 May 2020

Abstract: Formaldehyde is a recalcitrant pollutant, which is difficult to remove from wastewater using conventional and advanced treatments. The objective of this research was to remove the organic matter from formaldehyde from an industrial wastewater, achieving its total mineralization and allowing the reuse of the water. The treatment was based on the reaction of formaldehyde with nitric acid, which was first studied and modelled with synthetic waters. Results show that it was possible to almost completely mineralize the formaldehyde ( $>95 \%$ TOC removal) at the best conditions studied (1.72 $\mathrm{M}$ of nitric acid and $85{ }^{\circ} \mathrm{C}$ of temperature). The addition of $\mathrm{NaNO}_{2}$ accelerated this reaction; however, after $2 \mathrm{~h}$ of reaction time, its effect was negligible at the maximum concentration of $\mathrm{HNO}_{3}$ studied. The results obtained with industrial wastewater fit well with the model. It is concluded that formaldehyde in actual wastewaters can be successfully removed through direct mineralization with nitric acid, under selected conditions.

Keywords: formaldehyde; mineralization; modelling; industrial wastewater treatment; nitric acid; reaction mechanism

\section{Introduction}

Formaldehyde is a recalcitrant organic compound widely used around the world due to its high reactivity, colorless nature, stability, purity in commercial form and low cost [1]. It is used in many industrial products, including adhesives [2], paints [3], resins [4], textiles [5,6], wood-based panels [7], ethylene glycol [8] and other synthetic products in chemical and petrochemical plants [9], leading to concentrations of up to $10,000 \mathrm{mg} / \mathrm{L}$ in wastewater [10].

Among the studied methods for formaldehyde removal, biological ones are the most commonly considered despite the potential microbial inhibition, due to their cost effectiveness, easy operation and eco-friendly behavior [11]. Most that were studied were carried out with synthetic water at low concentrations, where the microbial inhibition is low and high removals of formaldehyde can be achieved [11-13]. However, the formaldehyde degradation can be reduced at high concentrations, especially if other toxic compounds are also present.

The state of the art shows the use of different advanced oxidation processes (AOPs) as pre-treatment for the removal of formaldehyde, such as photocatalysis, Fenton, photo-Fenton and electro-Fenton processes, ozonation with the addition of $\mathrm{H}_{2} \mathrm{O}_{2}$, catalytic ozonation and $\mathrm{H}_{2} \mathrm{O}_{2} / \mathrm{UV}$ process [14-17]. Fenton and photo-Fenton processes are able to degrade more than $90 \%$ of the formaldehyde in the wastewater, and the use of only $\mathrm{UV} / \mathrm{H}_{2} \mathrm{O}_{2}$ achieved almost $80 \%$ removal [18]. The electro-Fenton 
process applied to a highly formaldehyde concentrated water achieved the complete removal of formaldehyde, and 51\% mineralization [19]. Regarding ozone oxidation, different results have been found; generally, the addition of $\mathrm{H}_{2} \mathrm{O}_{2}$ and catalysts is usually required to achieve $80 \%$ formaldehyde reduction $[10,20]$. In these processes, the cost of operation is high due to the dosage of reagents and energy required. Furthermore, the matrix of the industrial wastewaters could reduce the efficiency of these treatments, as they are non-selective oxidation processes.

An alternative treatment is the reaction of formaldehyde with nitric acid. Previous studies have shown that nitric acid can be removed from wastewater by its reaction with formaldehyde and formic acid [21,22]. They found that the reaction happened after an induction period, which depended on the temperature and concentration of reagents. They suggested that accelerators of the reaction as sodium nitrite or nitrous acid could be used. The mechanism depends on the concentration of nitric acid-while high concentrations of $\mathrm{HNO}_{3}$ directly oxidize the formaldehyde to $\mathrm{NO}_{2}$ and $\mathrm{CO}_{2}$, as $\mathrm{HNO}_{3}$ concentration decreases, the oxidation of formaldehyde results in the formation of $\mathrm{NO}$ and $\mathrm{CO}_{2}$, as well as the formation of formic acid and $\mathrm{NO}_{2}$ [21-23]. They studied the degradation of nitric acid through its reaction with formaldehyde, performing the reaction at about $100{ }^{\circ} \mathrm{C}$ and optimizing the removal of nitric acid. Horváth et al. [24] focused on the study of the reaction through the formation of formic acid, working at ambient temperature and using high concentrations of nitric acid, always in presence of an accelerator. The induction period of the reaction was also studied by Healy [21], as a function of the temperature. It was concluded that reducing the induction time, high temperature and high nitric acid concentration are necessary.

Considering that the objective of this study is to treat an industrial wastewater to be able to reuse the water into the process, a complete mineralization of the formaldehyde is required. Therefore, a comprehensive study of the reaction of formaldehyde with nitric acid has been carried out. The process has been modeled with synthetic waters, studying different temperatures, concentrations of nitric acid and reaction times. Furthermore, the addition of sodium nitrite as an option to accelerate this reaction has been evaluated. Finally, the process has been applied to treat industrial wastewater. The results fit well with the model, and the treatment can be implemented at an industrial scale.

\section{Materials and Methods}

\subsection{Materials}

All used chemicals were of analytical grade. Formaldehyde (37\% w/w), stabilized with $10-15 \%$ methanol to prevent polymerization, was purchased from Sigma-Aldrich (Steinheim, Germany). A synthetic solution of $3500 \mathrm{mg} / \mathrm{L}$ of formaldehyde (corresponding TOC of $1400 \mathrm{mg} / \mathrm{L}$ ) was prepared with Milli-Q grade water to simulate the correspondent industrial wastewater highly contaminated with formaldehyde. Both nitric acid $(65 \% w / w)$ and sodium nitrite were supplied by Panreac S.A. (Barcelona, Spain). The industrial wastewater samples were received from the industrial plant to test the treatment. Samples were kept at ambient temperature to avoid the polymerization process of formaldehyde and characterized its previous use. Different samples were received, and the initial formaldehyde concentration varied between 927 and $3920 \mathrm{mg} / \mathrm{L}$.

\subsection{Experimental Procedure}

The reaction of formaldehyde with nitric acid has been studied at four different temperatures (50, 70, 85 and $\left.100^{\circ} \mathrm{C}\right)$ based on previous studies [21], adding different doses of sodium nitrite $(0,50$ and $100 \mathrm{mM}$ ). Sodium nitrite doses were substantially higher than those in the literature [24] to check their effect, trying to avoid the increase of temperature to obtain the degradation of formaldehyde and comparing those higher concentrations with the non-addition of nitrite. The concentrations of nitric acid $(0.17,0.86$ and $1.72 \mathrm{M})$ were selected to keep the amount of acid at a minimum, working at a molar ratio between nitric acid and formaldehyde of 2 with the lowest concentration, which should favor the formation of formic acid, according to Healy [21]. The higher concentrations of nitric 
acid imply molar ratios between nitric acid and formaldehyde of 9 and 18, above the stoichiometric molar ratio proposed by Healy [21] to achieve the direct degradation of formaldehyde. The synthetic formaldehyde solution and the corresponding amount of sodium nitrite were placed in a three-necked, round-bottomed flask, and this mixture was heated using a heating mantle up to the correspondent temperature in each experiment. Nitric acid was slowly dropped into the flask through one of the necks, which was subsequently closed. The produced gases passed through a reflux water condenser. All reactions were carried out for $120 \mathrm{~min}$, the maximum time permitted for this treatment step to be included in the industrial process, and samples were collected at 0, 15, 30, 60, 90 and $120 \mathrm{~min}$.

Total organic carbon (TOC) was measured using a TOC/TN analyzer multi N/C ${ }^{\circledR} 3100$ (Analytik Jena AG, Jena, Germany) with catalytic oxidation on cerium oxide at $850{ }^{\circ} \mathrm{C}$. Formaldehyde was measure by using GC/MS (Agilent Technologies, Santa Clara, CA, USA), GC model 7890A and MS model 75975C, with a J\&W HP-5ms GC Column ( $30 \mathrm{~m}, 0.25 \mathrm{~mm}, 0.25 \mu \mathrm{m}$, Agilent Technologies). The oven temperature program was $60^{\circ} \mathrm{C}(2 \mathrm{~min}) \rightarrow 7^{\circ} \mathrm{C} / \mathrm{min} \rightarrow 150{ }^{\circ} \mathrm{C} \rightarrow 15^{\circ} \mathrm{C} / \mathrm{min} \rightarrow 220^{\circ} \mathrm{C}$ $(10 \mathrm{~min}) \rightarrow 20{ }^{\circ} \mathrm{C} / \mathrm{min} \rightarrow 290^{\circ} \mathrm{C}(29 \mathrm{~min}) \rightarrow 25^{\circ} \mathrm{C} / \mathrm{min} \rightarrow 300^{\circ} \mathrm{C}$ ( $\left.2 \mathrm{~min}\right)$. The carrier gas was He at a constant flow of $1.0 \mathrm{~mL}$, injection temperature of $200{ }^{\circ} \mathrm{C}$ at splitless mode for $0.2 \mathrm{~min}$, ionization voltage of $70 \mathrm{eV}$, ion source temperature of $230^{\circ} \mathrm{C}$, quadrupole temperature of $150{ }^{\circ} \mathrm{C}$ and interphase temperature of $280^{\circ} \mathrm{C}$. Samples were prepared following the indications of Sugaya et al. [25].

\subsection{Experimental Design}

Response surface methodology (RSM) was used to study three independent variables, namely concentration of $\mathrm{HNO}_{3}$, temperature and concentration of $\mathrm{NaNO}_{2}$, in order to maximize TOC removal. The responses of each experiment were correlated with the three independent variables through an empirical second-degree polynomial equation (Equation (1), where $\mathrm{Y}$ is the dependent variable, $x_{i}$ and $x_{j}$ represent the independent variables and $b_{0}, b_{i}, b_{i i}$ and $b_{i j}$ are the corresponding regression coefficients). Two dependent variables were studied, the percentage of TOC removal after $30 \mathrm{~min}$ and $120 \mathrm{~min}$ of treatment. Analysis of variance (ANOVA) was used to analyze the models and to assess the influence that the experimental variables, as well as their interactive effects, has on the treatment of wastewater contaminated with formaldehyde. Statgraphics Centurion (Statpoint Technologies, Inc., Warrenton, VA, USA) was used for the statistical calculations. Response surfaces were drawn, considering one of the independent variables at a fixed value, and varying the other two.

$$
\mathrm{Y}=\mathrm{b}_{0}+\sum \mathrm{b}_{\mathrm{i}} \cdot \mathrm{x}_{\mathrm{i}}+\sum \mathrm{b}_{\mathrm{ii}} \cdot \mathrm{x}_{\mathrm{i}}^{2}+\sum \mathrm{b}_{\mathrm{ij}} \cdot \mathrm{x}_{\mathrm{i}} \cdot \mathrm{x}_{\mathrm{j}}
$$

\section{Results and Discussion}

\subsection{Assessment of Reaction Conditions to Mineralize Formaldehyde}

A systematic study of the effect of the variables was performed by measuring the TOC along the reaction. Mineralization was studied along the reaction time, regarding the $\mathrm{HNO}_{3}$ and $\mathrm{NaNO}_{2}$ concentrations at different temperatures (Figures 1 and 2).

The concentration of $0.17 \mathrm{M}$ of $\mathrm{HNO}_{3}$ achieved a maximum of $20 \%$ TOC removal at the best conditions tested ( $2 \mathrm{~h}$ of reaction time, 85 or $100{ }^{\circ} \mathrm{C}$ and $100 \mathrm{mM} \mathrm{NaNO}_{2}$; data not shown), and at the beginning of the reaction (15 min), remaining almost constant thereafter. For a higher formaldehyde mineralization, higher concentrations of $\mathrm{HNO}_{3}$ are needed, such as 0.86 and $1.72 \mathrm{M}$, as shown in Figures 1 and 2, respectively. At $0.86 \mathrm{M}$ of $\mathrm{HNO}_{3}$, the maximum TOC removal is $77 \%$, while $98 \%$ can be achieved at $1.72 \mathrm{M}$ of $\mathrm{HNO}_{3}$. In all cases the best temperature was $85^{\circ} \mathrm{C}$, and the presence of $\mathrm{NaNO}_{2}$ accelerated the reaction. 

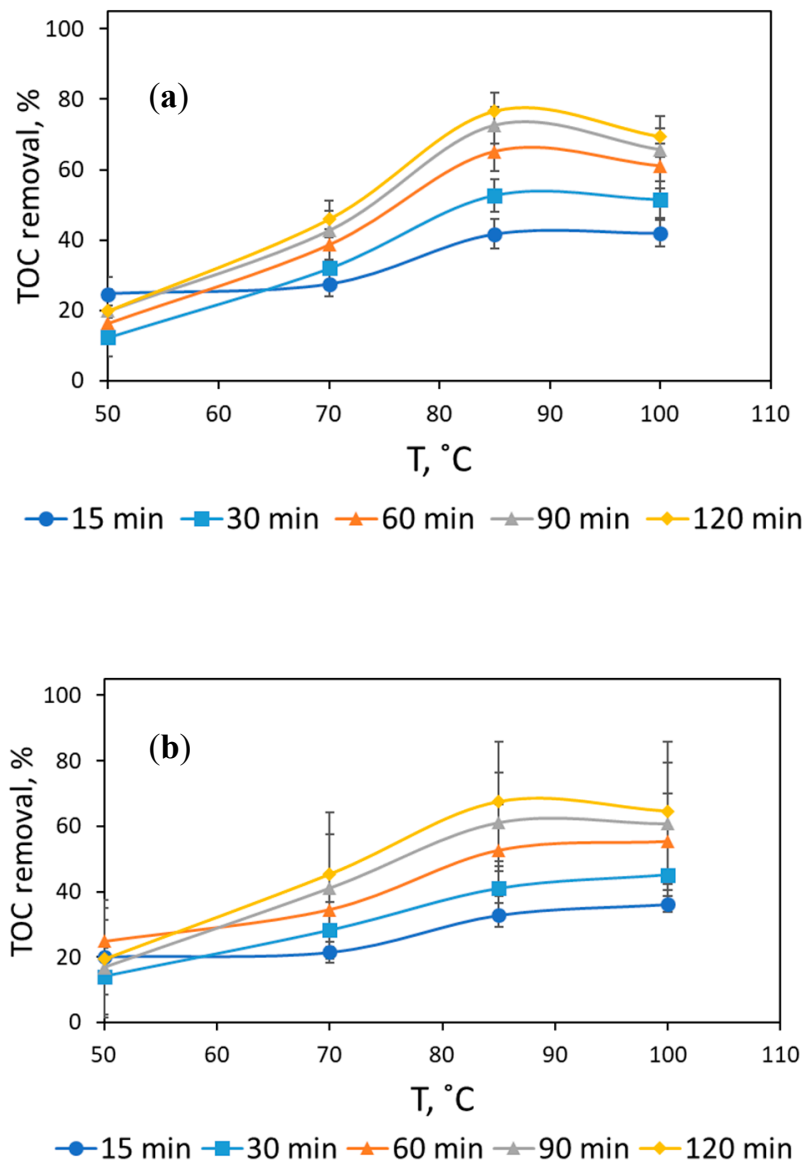

Figure 1. TOC removal at different reaction times depending on the temperature, adding (a) $100 \mathrm{mM}$ $\mathrm{NaNO}_{2}$ and (b) $50 \mathrm{mM} \mathrm{NaNO}_{2}$, and using $0.86 \mathrm{M} \mathrm{HNO}_{3}$.

At the best conditions, the mineralization was achieved after $2 \mathrm{~h}$, regardless the concentration of $\mathrm{NaNO}_{2}$ used. The role of nitrite in this reaction could be related with the increase amount of $\mathrm{HNO}_{3}$ in the reaction medium, according to the disproportionation reaction of $\mathrm{NO}_{2}$ in an acidic medium (Equation (2) [26]).

$$
3 \mathrm{NO}_{2}(\mathrm{ac})+3 \mathrm{H}_{(\mathrm{ac})}^{+} \rightleftarrows 2 \mathrm{NO}_{(\mathrm{g})}+\mathrm{HNO}_{3(\mathrm{ac})}+\mathrm{H}_{2} \mathrm{O}
$$

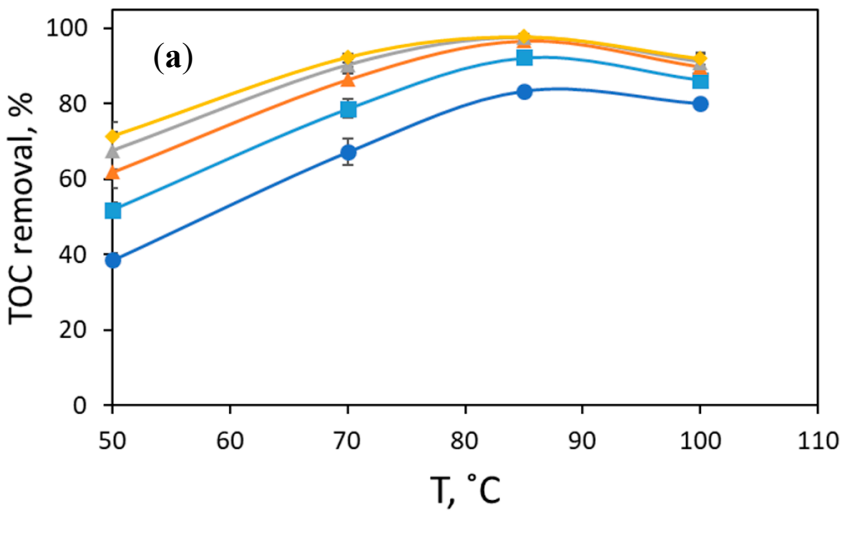

Figure 2. Cont. 

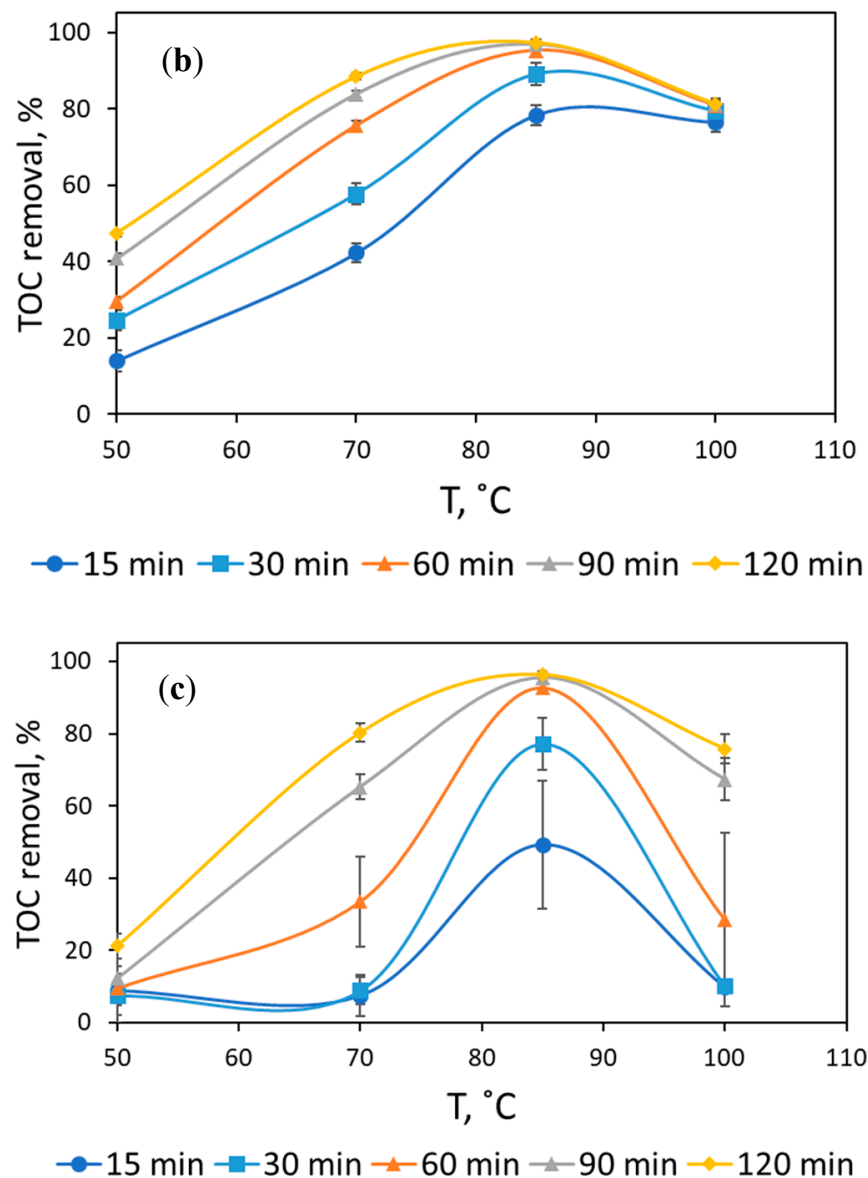

Figure 2. TOC removal at different reaction times depending on the temperature, adding (a) $100 \mathrm{mM}$ $\mathrm{NaNO}_{2}$, (b) $50 \mathrm{mM} \mathrm{NaNO}_{2}$ and (c) $0 \mathrm{mM} \mathrm{NaNO}_{2}$, and using $1.72 \mathrm{M} \mathrm{HNO}_{3}$.

An increase of temperature favors the kinetics of the reaction, which is observed up to $85^{\circ} \mathrm{C}$, but decreases thereafter. The profiles showed in Figures 1 and 2 mainly agree with those of the exothermic reversible reactions, in which too-high temperatures move away from equilibrium, working against the degradation process. This agrees with Healy [21], who proposed the reversible reaction of degradation of formaldehyde with nitric acid, which can happen through a direct degradation forming $\mathrm{NO}_{2}$ and $\mathrm{CO}_{2}$, or through the formation of formic acid as byproduct, and eventually resulting in $\mathrm{NO}_{2}$, $\mathrm{NO}$ and $\mathrm{CO}_{2}$, when the reactions were conducted at $100{ }^{\circ} \mathrm{C}$. He did not find $\mathrm{NO}$ in the gaseous stream when high amounts of $\mathrm{HNO}_{3}(>13 \mathrm{~N})$ were used in the reaction, assuming the direct degradation of formaldehyde, whereas at concentrations of $\mathrm{HNO}_{3}$ below $13 \mathrm{~N}$, reaction through the formation of formic acid should be considered. In fact, in our case, $\mathrm{NO}_{2}$ was clearly identified by its characteristic orange-reddish color at the beginning of the reaction at the higher values of temperature of 85 and $100{ }^{\circ} \mathrm{C}$. The production of this gaseous stream makes mandatory the implementation of treatment systems that are already implemented in the studied industrial site for other streams.

In summary, to optimize the industrial process, it is recommended to keep the best temperature at the beginning of the reaction and decrease it as the reaction proceeds and it is close to equilibrium. Being an exothermic reaction, it helps to reduce the amount of energy required to reach the optimum temperature.

Working at 70 and $100{ }^{\circ} \mathrm{C}$ with the highest amount of $\mathrm{HNO}_{3}$, between 80 and $90 \%$ of TOC was removed after $2 \mathrm{~h}$ of treatment, reaching higher TOC removal at shorter times when the concentration of $\mathrm{NaNO}_{2}$ increased (Figure 1). However, the effect of $\mathrm{NaNO}_{2}$ was negligible when the concentration of $\mathrm{HNO}_{3}$ was $0.86 \mathrm{M}$ (Figure 2) between using 50 and $100 \mathrm{mM}$ of $\mathrm{NaNO}_{2}$. However, at this low amount of $\mathrm{HNO}_{3}$, the addition of $\mathrm{NaNO}_{2}$ is required to observe any degradation in $2 \mathrm{~h}$ of reaction time. 
$50{ }^{\circ} \mathrm{C}$ of reaction temperature with the highest concentrations of both $\mathrm{HNO}_{3}$ and $\mathrm{NaNO}_{2}$ achieved a $70 \%$ TOC removal after $2 \mathrm{~h}$ of treatment (Figure 1), which was drastically reduced as the concentration of $\mathrm{HNO}_{3}$ decreased (Figure 2).

The profiles of TOC removal during the treatment moved from no increase of TOC removal to a power profile of TOC removal with the increasing concentration of $\mathrm{HNO}_{3}$, temperature and concentration of $\mathrm{NaNO}_{2}$, up to those close to the best ones. It can be concluded that at the best conditions, the reaction occurred mainly in a single step with the direct mineralization of the formaldehyde, as Healy [21] proposed, while as the conditions of the reaction move away from the best ones, the oxidation of formaldehyde mainly follows the two stages through the formation of $\mathrm{HCOOH}$, slowing down the kinetics of the process [21,24]. Complete mineralization could not be observed at low concentrations of $\mathrm{HNO}_{3}$ in $2 \mathrm{~h}$ of treatment, probably due to the reaction in two stages from $\mathrm{CH}_{2} \mathrm{O}$ to $\mathrm{HCOOH}$ and then $\mathrm{CO}_{2}, \mathrm{NO}$ and $\mathrm{NO}_{2}$; whereas at $1.72 \mathrm{M}$ of $\mathrm{HNO}_{3}, 96 \%$ of TOC removal can be achieved probably through direct mineralization of $\mathrm{CH}_{2} \mathrm{O}$ to $\mathrm{CO}_{2}$ and $\mathrm{NO}_{2}$. Higher concentrations of $\mathrm{HNO}_{3}$ do not meaningfully improve the reaction ( $2.3 \mathrm{M}$ of $\mathrm{HNO}_{3}, 97 \%$ of TOC), which seems to indicate that part of the $\mathrm{CH}_{2} \mathrm{O}$ is degraded into $\mathrm{HCOOH}$ following the two-stage path.

\subsection{Statistical Analysis}

TOC removal after $30 \mathrm{~min}, \mathrm{Y}_{1}$, and $120 \mathrm{~min}, \mathrm{Y}_{2}$, and the matrix of experiments are shown in Table 1. The empirical quadratic correlations between dependent and independent variables are shown in Equations (3) and (4) for $Y_{1}$ and $Y_{2}$, respectively.

$$
\begin{gathered}
\mathrm{Y}_{1 \text { predicted }}=-54.90+0.13 \cdot \mathrm{NaNO}_{2}-35.58 \cdot \mathrm{HNO}_{3}+1.71 \cdot \mathrm{T} \\
-0.0033 \cdot \mathrm{NaNO}_{2}{ }^{2}+0.26 \cdot \mathrm{NaNO}_{2} \cdot \mathrm{HNO}_{3}+0.0037 \cdot \mathrm{NaNO}_{2} \cdot \mathrm{T}+ \\
+8.81 \cdot \mathrm{HNO}_{3}{ }^{2}+0.48 \cdot \mathrm{HNO}_{3} \cdot \mathrm{T}-0.012 \cdot \mathrm{T}^{2} \\
\mathrm{Y}_{2 \text { predicted }}=-109.48+0.47 \cdot \mathrm{NaNO}_{2}+5.42 \cdot \mathrm{HNO}_{3}+2.55 \cdot \mathrm{T} \\
-0.0022 \cdot \mathrm{NaNO}_{2}{ }^{2}+0.065 \cdot \mathrm{NaNO}_{2} \cdot \mathrm{HNO}_{3}-0.0010 \cdot \mathrm{NaNO}_{2} \cdot \mathrm{T}+ \\
+2.52 \cdot \mathrm{HNO}_{3}{ }^{2}+0.42 \cdot \mathrm{HNO}_{3} \cdot \mathrm{T}-0.015 \cdot \mathrm{T}^{2}
\end{gathered}
$$

\begin{tabular}{|c|c|c|c|c|c|c|}
\hline $\mathrm{NaNO}_{2}, \mathrm{mM}$ & $\mathrm{HNO}_{3}, \mathrm{M}$ & $\mathrm{T},{ }^{\circ} \mathrm{C}$ & $Y_{1, \text { experimental }} \%$ & $\mathrm{Y}_{1, \text { predicted }}, \%$ & $Y_{2, \text { experimental }} \%$ & $Y_{2, \text { predicted }}, \%$ \\
\hline 0 & 0.17 & 50 & 0.7 & -2.5 & 1.4 & -16.0 \\
\hline 0 & 0.17 & 70 & 0.7 & 3.3 & 2.8 & -0.4 \\
\hline 0 & 0.17 & 85 & 5.6 & 1.0 & 4.9 & 3.1 \\
\hline 0 & 0.17 & 100 & 2.8 & -6.9 & 7.6 & -0.2 \\
\hline 0 & 0.86 & 50 & 2.1 & -4.3 & 0.0 & 4.2 \\
\hline 0 & 0.86 & 70 & 0.7 & 8.1 & 1.4 & 25.5 \\
\hline 0 & 0.86 & 85 & 0 & 10.7 & 2.1 & 33.5 \\
\hline 0 & 0.86 & 100 & 4.2 & 7.8 & 40.0 & 34.5 \\
\hline 0 & 1.72 & 50 & 7.5 & 5.2 & 21.2 & 32.6 \\
\hline 0 & 1.72 & 70 & 8.9 & 25.8 & 80.2 & 61.2 \\
\hline 0 & 1.72 & 85 & 77.2 & 34.6 & 96.3 & 74.6 \\
\hline 0 & 1.72 & 100 & 10.2 & 37.8 & 75.8 & 81.1 \\
\hline 50 & 0.17 & 50 & 8.9 & 7.1 & 7.5 & 0.1 \\
\hline 50 & 0.17 & 70 & 8.3 & 16.5 & 5.5 & 14.5 \\
\hline 50 & 0.17 & 85 & 5 & 17.0 & 11.4 & 17.4 \\
\hline 50 & 0.17 & 100 & 10.9 & 11.9 & 3.1 & 13.3 \\
\hline 50 & 0.86 & 50 & 14.1 & 14.4 & 19.5 & 22.4 \\
\hline 50 & 0.86 & 70 & 28.2 & 30.5 & 45.4 & 42.7 \\
\hline 50 & 0.86 & 85 & 41 & 35.9 & 67.4 & 49.9 \\
\hline 50 & 0.86 & 100 & 45.1 & 35.7 & 64.5 & 50.2 \\
\hline 50 & 1.72 & 50 & 24.6 & 35.3 & 47.4 & 53.6 \\
\hline 50 & 1.72 & 70 & 57.7 & 59.5 & 88.4 & 81.2 \\
\hline
\end{tabular}

Table 1. Experiments performed under different conditions and the responses (TOC removal after $30 \mathrm{~min}, \mathrm{Y}_{1}$, and TOC removal after $120 \mathrm{~min}, \mathrm{Y}_{2}$ ) obtained experimentally and predicted by the model. 
Table 1. Cont

\begin{tabular}{|c|c|c|c|c|c|c|}
\hline $\mathrm{NaNO}_{2}, \mathrm{mM}$ & $\mathrm{HNO}_{3}, \mathrm{M}$ & $\mathrm{T},{ }^{\circ} \mathrm{C}$ & $Y_{1, \text { experimental }} \%$ & $Y_{1, \text { predicted }}, \%$ & $\mathrm{Y}_{2, \text { experimental }} \%$ & $\mathrm{Y}_{2, \text { predicted }}, \%$ \\
\hline 50 & 1.72 & 85 & 89 & 71.2 & 97.3 & 93.8 \\
\hline 50 & 1.72 & 100 & 79.4 & 77.1 & 81.2 & 99.6 \\
\hline 100 & 0.17 & 50 & 10.5 & 0.2 & 10.5 & 5.3 \\
\hline 100 & 0.17 & 70 & 11.2 & 13.4 & 9.1 & 18.7 \\
\hline 100 & 0.17 & 85 & 10.5 & 16.6 & 10.5 & 20.8 \\
\hline 100 & 0.17 & 100 & 16.8 & 14.2 & 18.2 & 15.9 \\
\hline 100 & 0.86 & 50 & 12.3 & 16.7 & 19.9 & 29.9 \\
\hline 100 & 0.86 & 70 & 31.9 & 36.4 & 46.0 & 49.2 \\
\hline 100 & 0.86 & 85 & 52.7 & 44.6 & 76.8 & 55.6 \\
\hline 100 & 0.86 & 100 & 51.4 & 47.2 & 69.5 & 55.1 \\
\hline 100 & 1.72 & 50 & 51.8 & 48.9 & 71.5 & 63.9 \\
\hline 100 & 1.72 & 70 & 78.7 & 76.9 & 92.4 & 90.4 \\
\hline 100 & 1.72 & 85 & 92.2 & 91.2 & 97.8 & 102.3 \\
\hline 100 & 1.72 & 100 & 86.4 & 100.0 & 92.0 & 107.2 \\
\hline
\end{tabular}

The results for the analysis of variance (ANOVA) for the quadratic model are presented in Tables 2 and 3 for both responses TOC removal after $30 \mathrm{~min}, \mathrm{Y}_{1}$, and after $120 \mathrm{~min}, \mathrm{Y}_{2}$, respectively. The ANOVA table divides the TOC removal variability into separated pieces for each factor. It proves the statistical significance of each factor by comparing their mean square and an estimation of the experimental error. For the case of $\mathrm{Y}_{1}$ (response is the TOC removal after $30 \mathrm{~min}$, Table 2), there were five factors with a $p$-value lower than 0.05 . A factor is more significant when the $\mathrm{F}$ value is bigger and $p$-value is smaller [27]; therefore, in this case the more significant factors were the concentration of both $\mathrm{NaNO}_{2}$ and $\mathrm{HNO}_{3}$. Regarding square $\mathrm{R}$, the model is able to explain $85.79 \%$ of the variability of TOC removal after $30 \mathrm{~min}$. However, adjusted square- $\mathrm{R}$ is more adequate to compare models with a different number of independent variables, and this was $80.88 \%$.

Table 2. ANOVA for the response surface quadratic model where response was TOC removal after $30 \mathrm{~min}, \mathrm{Y}_{1}$.

\begin{tabular}{ccccccc}
\hline Source & Sum of Squares & $\mathbf{d f}$ & Mean Square & F Value & $\boldsymbol{p}$-Value & \\
\hline $\mathrm{x}_{1}: \mathrm{NaNO}_{2}$ concentration & 6272.5 & 1 & 6272.5 & 36.46 & 0 & Significant \\
$\mathrm{x}_{2}: \mathrm{HNO}_{3}$ concentration & $13,034.8$ & 1 & $13,034.8$ & 75.77 & 0 & Significant \\
$\mathrm{x}_{3}:$ Temperature & 2665.5 & 1 & 2665.5 & 15.49 & 0.0006 & Significant \\
$\mathrm{x}_{1}{ }^{2}$ & 541.2 & 1 & 541.2 & 3.15 & 0.0878 & \\
$\mathrm{x}_{1} \cdot \mathrm{x}_{2}$ & 1688.8 & 1 & 1688.8 & 9.82 & 0.0042 & Significant \\
$\mathrm{x}_{1} \cdot \mathrm{x}_{3}$ & 279.0 & 1 & 279.0 & 1.62 & 0.2141 & \\
$\mathrm{x}_{2}{ }^{2}$ & 217.5 & 1 & 217.5 & 1.26 & 0.2711 & \\
$\mathrm{x}_{2} \cdot \mathrm{x}_{3}$ & 1131.3 & 1 & 1131.3 & 6.58 & 0.0165 & Significant \\
$\mathrm{x}_{3}{ }^{2}$ & 450.3 & 1 & 450.3 & 2.62 & 0.1177 & \\
Total error & 4472.7 & 26 & 172.0 & & & \\
Total (cor.) & $31,483.7$ & 35 & & & & \\
Square- $\mathrm{R}=85.79 \%$ & & & & & \\
\hline
\end{tabular}

In the case of $\mathrm{Y}_{2}$ (response is the TOC removal after $120 \mathrm{~min}$, Table 3), there were only three factors with a $p$-value lower than 0.05 , with the concentration of $\mathrm{HNO}_{3}$ being the most significant of all. The relevance of the concentration of $\mathrm{NaNO}_{2}$ on this response was much lower than for $\mathrm{Y}_{1}$, due to the effect that the reaction time has on the removal of TOC. Therefore, it can be concluded that the effect of the concentration of $\mathrm{NaNO}_{2}$ is much more important at short reaction times, being less significant when the reaction time increases. The model can explain $87.78 \%$ of the variability of TOC removal after $120 \mathrm{~min}$, being the adjusted square-R $83.54 \%$. 
Table 3. ANOVA for the response surface quadratic model where response was TOC removal after $120 \min , Y_{2}$.

\begin{tabular}{ccccccc}
\hline Source & Sum of Squares & df & Mean Square & F Value & $p$-Value & \\
\hline $\mathrm{x}_{1}: \mathrm{NaNO}_{2}$ concentration & 3344.6 & 1 & 3344.6 & 15.72 & 0.0005 & Significant \\
$\mathrm{x}_{2}: \mathrm{HNO}_{3}$ concentration & $29,209.4$ & 1 & $29,209.4$ & 137.26 & 0 & Significant \\
$\mathrm{x}_{3}:$ Temperature & 4294.7 & 1 & 4294.7 & 20.18 & 0.0001 & Significant \\
$\mathrm{x}_{1}{ }^{2}$ & 232.2 & 1 & 232.2 & 1.09 & 0.3058 & \\
$\mathrm{x}_{1} \cdot \mathrm{x}_{2}$ & 101.4 & 1 & 101.4 & 0.48 & 0.4962 & \\
$\mathrm{x}_{1} \cdot \mathrm{x}_{3}$ & 21.8 & 1 & 21.8 & 0.10 & 0.7515 & \\
$\mathrm{x}_{2}{ }^{2}$ & 17.8 & 1 & 17.8 & 0.08 & 0.7746 & \\
$\mathrm{x}_{2} \cdot \mathrm{x}_{3}$ & 884.4 & 1 & 884.4 & 4.16 & 0.0518 & \\
$\mathrm{x}_{3}{ }^{2}$ & 675.9 & 1 & 675.9 & 3.18 & 0.0864 & \\
Total error & 5532.8 & 26 & 212.8 & & & \\
Total (cor.) & $45,265.1$ & 35 & & & & \\
Square $\mathrm{R}=87.78 \%$ & & & & & &
\end{tabular}

\subsection{Response Surface Methodology to Model the Mineralization of Formaldehyde}

If the temperature is fixed at $85^{\circ} \mathrm{C}$, the effect of the concentration of $\mathrm{HNO}_{3}$ on the TOC removal was greater than the concentration of $\mathrm{NaNO}_{2}$, both after 30 and 120 min of reaction time (Figure 3a,b, respectively). However, there is a clear difference on the effect of $\mathrm{NaNO}_{2}$ on $\mathrm{TOC}$ removal depending on the reaction time. After $30 \mathrm{~min}$, the influence of $\mathrm{NaNO}_{2}$ on the TOC removal is almost as significant as the influence of $\mathrm{HNO}_{3}$, increasing the TOC removal as both concentrations, $\mathrm{NaNO}_{2}$ and $\mathrm{HNO}_{3}$, increase, with the effect of $\mathrm{NaNO}_{2}$ being higher when the concentration of $\mathrm{HNO}_{3}$ was higher. Therefore, it is possible to drastically decrease the reaction time, reaching more than $90 \%$ TOC removal in $30 \mathrm{~min}$ working at $85^{\circ} \mathrm{C}$, with the highest doses tested of $\mathrm{HNO}_{3}$ and $\mathrm{NaNO}_{2}$ (Figure 3a). Working at $85^{\circ} \mathrm{C}$, however, at the higher concentration of $\mathrm{HNO}_{3}$, more than $95 \%$ removal of TOC after $2 \mathrm{~h}$ can be achieved, regardless the concentration of $\mathrm{NaNO}_{2}$ (Figure 3b). At that reaction time, the influence of $\mathrm{NaNO}_{2}$ is not as meaningful as it was at shorter reaction times, showing a slight increase of TOC removal as the concentration of $\mathrm{NaNO}_{2}$ increased (Figure 3b). Therefore, the models help to look for optimum conditions and find the critical parameters.

The fixed doses of $\mathrm{NaNO}_{2}$ and $\mathrm{HNO}_{3}$ to represent response surfaces were the maximum dose tested for each one after $30 \mathrm{~min}$ of reaction time (Figures 4 and 5, respectively). When the concentration of $\mathrm{NaNO}_{2}$ was kept fixed at $100 \mathrm{mM}$, the influence of the concentration of $\mathrm{HNO}_{3}$ was greater than the influence of the temperature on the TOC removal after $30 \mathrm{~min}$ of treatment (Figure 4). As the concentration of $\mathrm{HNO}_{3}$ increased, the TOC removal increased as well, reaching higher values of TOC removal when an additional high temperature was applied during the reaction. As can be observed in Figures 3 and 4 , at a lower amount of $\mathrm{HNO}_{3}$, the effect of other variables is negligible, regardless of the concentration of $\mathrm{NaNO}_{2}$, reaction time (Figure 3) or temperature (Figure 4). However, as the dose of $\mathrm{HNO}_{3}$ increases, their effect becomes more significant, at least after $30 \mathrm{~min}$ of reaction time (Figures $3 \mathrm{a}$ and 4). Therefore, it seems that a minimum amount of $\mathrm{HNO}_{3}$ is needed to keep the reaction working, and to improve it by optimizing the rest of the parameters. 
(a)

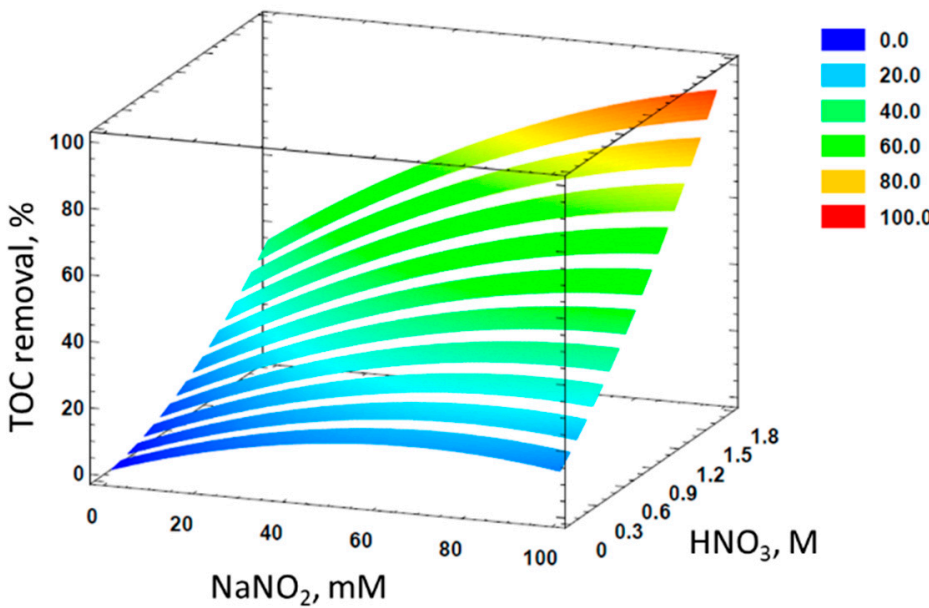

(b)

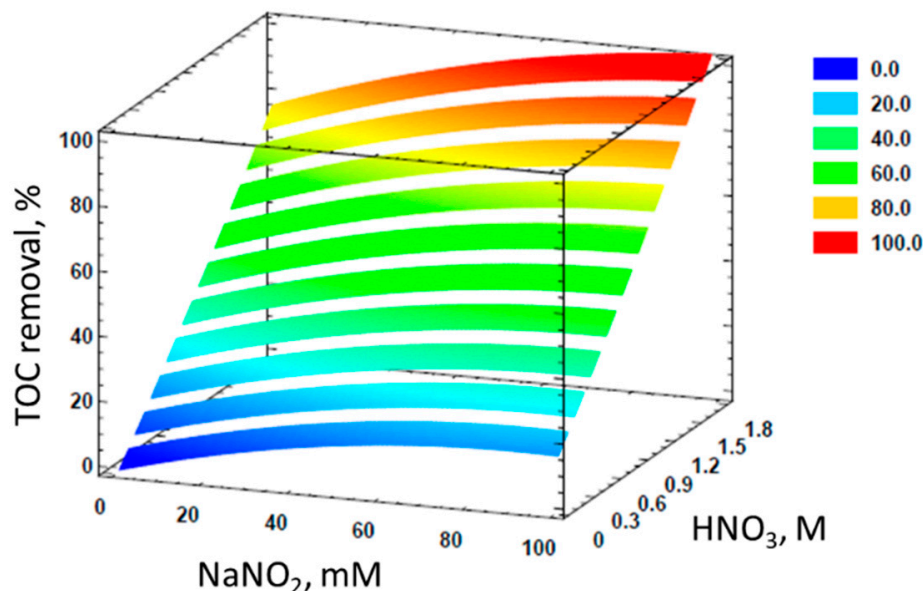

Figure 3. Response surfaces to assess the effect of the concentration of both $\mathrm{NaNO}_{2}$ and $\mathrm{HNO}_{3}$ on $\mathrm{TOC}$ removal after (a) 30 and (b) 120 min of treatment, at a fixed temperature of $85^{\circ} \mathrm{C}$.

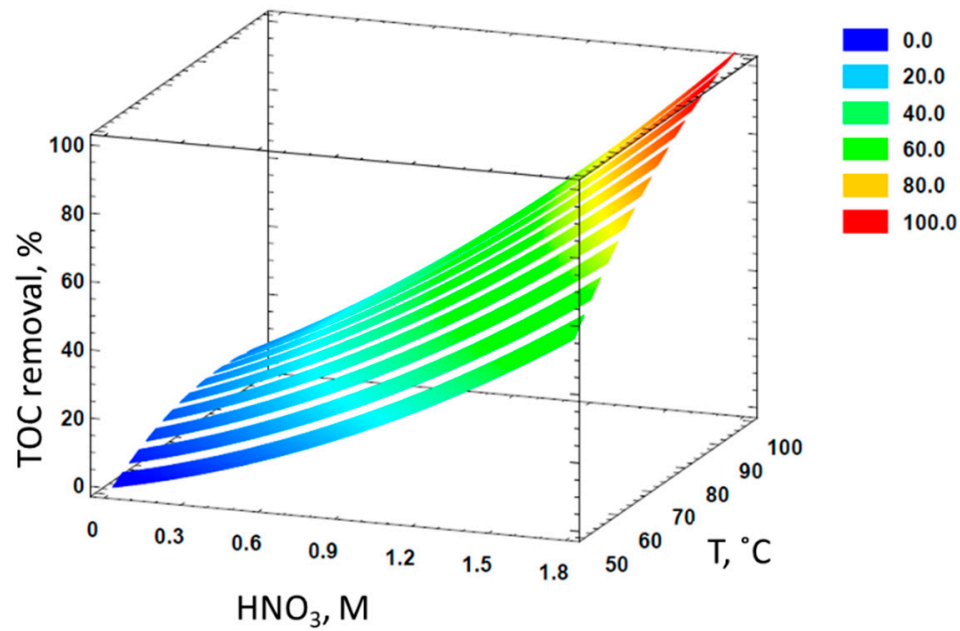

Figure 4. Response surfaces to assess the effect of both temperature and concentration of $\mathrm{HNO}_{3}$ on TOC removal after 30 min of treatment, at a fixed dose of $\mathrm{NaNO}_{2}$ of $100 \mathrm{mM}$.

Finally, by fixing the amount of $\mathrm{HNO}_{3}$ at the maximum one, after 30 min of reaction time (Figure 5), the effect of the other two variables, concentration of $\mathrm{NaNO}_{2}$ and temperature, can be observed. TOC removal increases as both the concentration of $\mathrm{NaNO}_{2}$ and temperature increase. 
However, the effect of the temperature was different depending on the dose of $\mathrm{NaNO}_{2}$ used in the reaction. As the concentration of $\mathrm{NaNO}_{2}$ increases, the effect of increasing the temperature is high.

The surface models predict the increase of the TOC removal as the temperature increases, although between 85 and $100{ }^{\circ} \mathrm{C}$, TOC removal remains constant or even decreases, and the models struggle to predict that behavior.

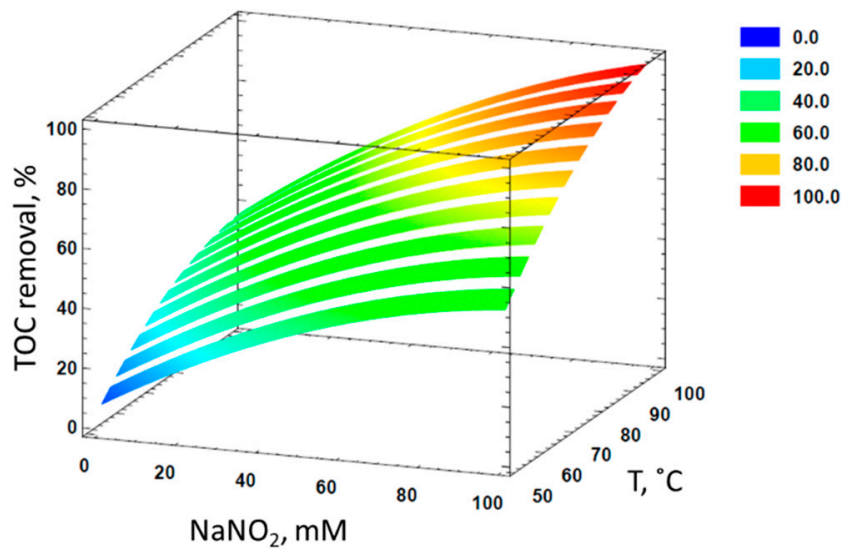

Figure 5. Response surfaces to assess the effect of both dose of $\mathrm{NaNO}_{2}$ and temperature on TOC removal after $30 \mathrm{~min}$ of treatment at a fixed dose of $\mathrm{HNO}_{3}$ of $1.72 \mathrm{M}$.

Wastewater containing formaldehyde from an industrial process was used to validate the models obtained for the mineralization of formaldehyde at the best studied temperature and after $120 \mathrm{~min}$ of reaction time. RSM model at $85^{\circ} \mathrm{C}$ predicts the behavior of the industrial wastewater quite well (Figure 6), although the model tendency seems to point out to a complete removal of TOC at higher concentration of $\mathrm{HNO}_{3}$. However, the experimental data prove that part of the formaldehyde is not completely degraded, probably because formic acid is formed, whose mineralization is slower that the one of formaldehyde, explaining the remained TOC at higher concentrations of nitric acid. Therefore, high concentrations of $\mathrm{HNO}_{3}$ favor the direct mineralization of formaldehyde, but degradation to formic acid could still occur.

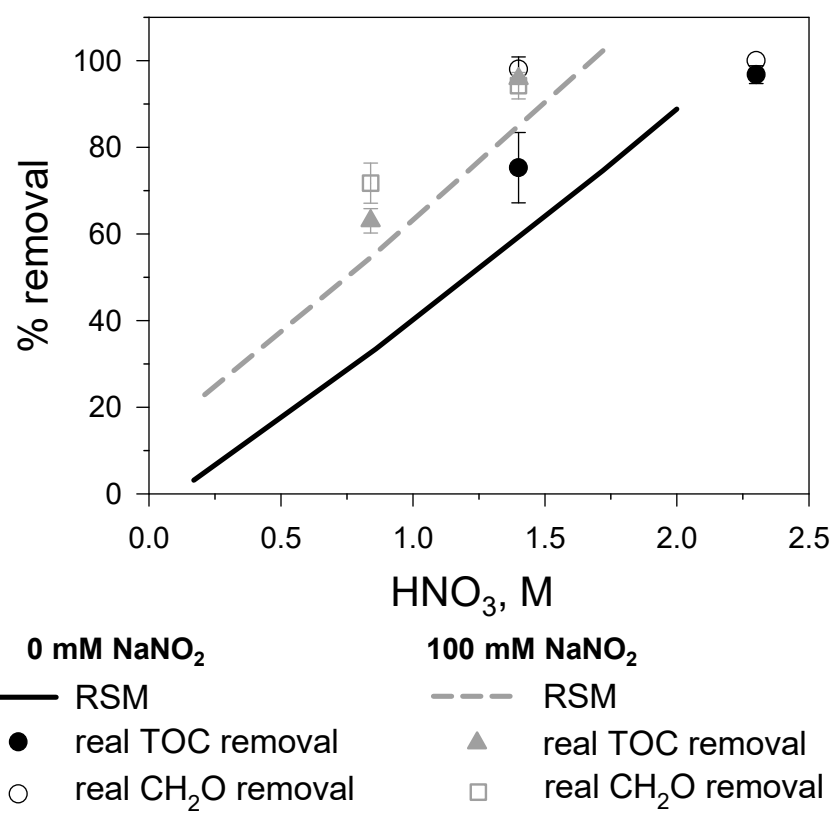

Figure 6. RSM for $85^{\circ} \mathrm{C}$ and the corresponding real values for TOC removal and formaldehyde removal. 
Working with $100 \mathrm{mM}$ of $\mathrm{NaNO}_{2}$, the TOC removal was almost the same as predicted by the model; the same happens without addition of $\mathrm{NaNO}_{2}$ at the model conditions (1.4 $\mathrm{M}$ of $\mathrm{HNO}_{3}$ ) or near the limits of the model (2.3 $\mathrm{M}_{\text {of }} \mathrm{HNO}_{3}$ ) (Figure 6).

Interestingly, if TOC removal is compared with formaldehyde removal for the industrial wastewater (Figure 6), working at $85^{\circ} \mathrm{C}$, it is observed that formaldehyde and TOC removals were always practically the same, reinforcing the hypothesis of the removal of formaldehyde through direct mineralization.

$$
\begin{gathered}
\% \mathrm{TOC}_{\text {removal }, 85}{ }^{\circ} \mathrm{C}=-3.95+41.34 \cdot \mathrm{HNO}_{3}+0.38 \cdot \mathrm{NaNO}_{2}+0.065 \cdot \mathrm{HNO}_{3} . \\
\mathrm{NaNO}_{2}+2.52 \cdot \mathrm{HNO}_{3}{ }^{2}-0.022 \cdot \mathrm{NaNO}_{2}{ }^{2}
\end{gathered}
$$

\subsection{Assessment of the Influence of $\mathrm{HNO}_{3} / \mathrm{CH}_{2} \mathrm{O}$ Ratio}

Table 4 shows the effect of the different parameters for different formaldehyde concentrations in industrial wastewater (Table 4). It is important to consider the $\mathrm{HNO}_{3} / \mathrm{CH}_{2} \mathrm{O}$ molar ratio in each case. In the table, the experiments are ordered according to the $\mathrm{HNO}_{3}$ concentration in the reaction.

Results show that when the concentration of $\mathrm{HNO}_{3}$ decreases, the removal of $\mathrm{CH}_{2} \mathrm{O}$ tends to decrease, although both the temperature and the concentration of $\mathrm{NaNO}_{2}$ also influence the reaction. Equations (5)-(7) [21] show the possible reactions between $\mathrm{HNO}_{3}$ and $\mathrm{CH}_{2} \mathrm{O}$ depending on the concentration of $\mathrm{HNO}_{3}$ in the reaction medium: high concentration favors reaction $5(>16 \mathrm{M})$; concentrations around $1 \mathrm{M}$ favor reaction 6; and lower concentrations favor reaction $7(<0.5 \mathrm{M})$. The results shown in Table 4 agree with the Healy observations; when more than $1 \mathrm{M}$ of $\mathrm{HNO}_{3}$ was used, a complete degradation of formaldehyde directly into $\mathrm{CO}_{2}$ and a mixture of $\mathrm{NO}$ and $\mathrm{NO}_{2}$ is achieved. As the concentration of $\mathrm{HNO}_{3}$ decreased, the kinetics of the reaction did too, with it not being possible to completely degrade formaldehyde when the concentration of $\mathrm{HNO}_{3}$ decreases below $1 \mathrm{M}$.

$$
\begin{gathered}
4 \mathrm{HNO}_{3}+\mathrm{CH}_{2} \mathrm{O} \rightleftarrows 4 \mathrm{NO}_{2}+\mathrm{CO}_{2}+3 \mathrm{H}_{2} \mathrm{O} \\
4 \mathrm{HNO}_{3}+3 \mathrm{CH}_{2} \mathrm{O} \rightleftarrows 4 \mathrm{NO}+3 \mathrm{CO}_{2}+5 \mathrm{H}_{2} \mathrm{O} \\
2 \mathrm{HNO}_{3}+\mathrm{CH}_{2} \mathrm{O} \rightleftarrows \mathrm{HCOOH}+2 \mathrm{NO}_{2}+\mathrm{H}_{2} \mathrm{O}
\end{gathered}
$$

The removal of $\mathrm{CH}_{2} \mathrm{O}$ also decreases when the molar ratio $\mathrm{HNO}_{3} / \mathrm{CH}_{2} \mathrm{O}$ is lower. When more than $1 \mathrm{M}$ of $\mathrm{HNO}_{3}$ was used, the $\mathrm{HNO}_{3} / \mathrm{CH}_{2} \mathrm{O}$ molar ratio was kept higher than 20. The decrease of $\mathrm{HNO}_{3}$ below $1 \mathrm{M}$ decreased the degradation of formaldehyde, even working at a $\mathrm{HNO}_{3} / \mathrm{CH}_{2} \mathrm{O}$ molar ratio of 12, enough above the stoichiometric ratio between $\mathrm{HNO}_{3}$ and $\mathrm{CH}_{2} \mathrm{O}$. For that reason, it can be concluded that the ratio among $\mathrm{HNO}_{3}$ and $\mathrm{CH}_{2} \mathrm{O}$ must be high enough, but on the other hand, a minimum concentration of $\mathrm{HNO}_{3}$ must also be used.

Table 4. Formaldehyde removal achieved by varying nitric acid concentration, temperature, sodium nitrite and formaldehyde concentration, working with industrial wastewater.

\begin{tabular}{cccccc}
\hline $\mathbf{H N O}_{3}, \mathbf{M}$ & $\mathbf{T},{ }^{\circ} \mathbf{C}$ & $\mathrm{NaNO}_{2}, \mathbf{m M}$ & $\mathbf{C H}_{\mathbf{2}} \mathbf{O}, \mathbf{m g} / \mathbf{L}$ & $\begin{array}{c}\mathrm{HNO}_{3} / \mathrm{CH}_{2} \mathbf{O} \\
\text { Molar Ratio }\end{array}$ & $\begin{array}{c}\% \mathrm{CH}_{2} \mathbf{O} \\
\text { Removed }\end{array}$ \\
\hline 5.7 & 100 & 0 & 1465 & 117 & 100 \\
5.7 & 85 & 0 & 1737 & 99 & 100 \\
5.7 & 70 & 0 & 1737 & 99 & 100 \\
4.35 & 85 & 0 & 1363 & 96 & 100 \\
4.35 & 85 & 0 & 1460 & 89 & 100 \\
4.35 & 70 & 0 & 927 & 141 & 95.3 \\
2.3 & 100 & 0 & 1205 & 57 & 100 \\
2.3 & 85 & 0 & 1778 & 39 & 100 \\
2.3 & 70 & 0 & 1416 & 49 & 100 \\
1.7 & 85 & 100 & 2204 & 22 & 97.7 \\
1.7 & 85 & 100 & 2326 & 22 & 92.4 \\
1.4 & 85 & 0 & 1768 & 24 & 100 \\
\hline
\end{tabular}


Table 4. Cont.

\begin{tabular}{cccccc}
\hline $\mathbf{H N O}_{3}, \mathbf{M}$ & $\mathbf{T},{ }^{\circ} \mathbf{C}$ & $\mathrm{NaNO}_{2}, \mathbf{m M}$ & $\mathbf{C H}_{\mathbf{2}} \mathbf{O}, \mathbf{m g} / \mathbf{L}$ & $\begin{array}{c}\mathrm{HNO}_{3} / \mathrm{CH}_{\mathbf{2}} \mathbf{O} \\
\text { Molar Ratio }\end{array}$ & $\begin{array}{c}\% \mathrm{CH}_{2} \mathbf{O} \\
\text { Removed }\end{array}$ \\
\hline 1.4 & 70 & 0 & 2001 & 21 & 100 \\
0.91 & 85 & 100 & 2278 & 12 & 68.4 \\
0.91 & 70 & 100 & 2278 & 12 & 58.7 \\
0.20 & 100 & 100 & 3920 & 1.5 & 77.3 \\
0.20 & 70 & 100 & 3920 & 1.5 & 77.8 \\
0.176 & 85 & 0 & 2399 & 2.2 & 20 \\
0.176 & 70 & 0 & 2399 & 2.2 & 11 \\
0.066 & 70 & 0 & 1922 & 1.0 & 29.1 \\
0.066 & 85 & 0 & 1922 & 1.0 & 13 \\
\hline
\end{tabular}

Table 4 shows different initial concentrations of formaldehyde due to the variability of wastewater, but they are all in the same magnitude order. For that reason, additional experiments with higher concentrations of formaldehyde were performed (Table 5), in the absence of $\mathrm{NaNO}_{2}$ and using similar concentrations of $\mathrm{HNO}_{3}$ than in the previous experiments. The removal of $\mathrm{CH}_{2} \mathrm{O}$ was higher than $98 \%$ in these cases, from $5.5 \mathrm{M}$ of $\mathrm{HNO}_{3}$ with a $3.8 \mathrm{HNO}_{3} / \mathrm{CH}_{2} \mathrm{O}$ molar ratio to $0.66 \mathrm{M}$ of $\mathrm{HNO}_{3}$ with a $0.5 \mathrm{HNO}_{3} / \mathrm{CH}_{2} \mathrm{O}$ molar ratio (Table 5). It seems that the increase of formaldehyde concentration increases the kinetics of the reaction, with it being necessary to lower amount of $\mathrm{HNO}_{3}$ to achieve high $\mathrm{CH}_{2} \mathrm{O}$ removals.

Table 5. Formaldehyde removal achieved by varying nitric acid concentration, working with highly concentrated synthetic wastewater.

\begin{tabular}{cccccc}
\hline $\mathbf{H N O}_{3}, \mathbf{M}$ & $\mathbf{T},{ }^{\circ} \mathbf{C}$ & $\mathbf{N a N O}_{2}, \mathbf{m M}$ & $\mathbf{C H}_{2} \mathbf{O}, \mathbf{m g} / \mathbf{L}$ & $\begin{array}{c}\mathrm{HNO}_{3} / \mathrm{CH}_{\mathbf{2}} \mathrm{O} \\
\text { Molar Ratio }\end{array}$ & $\begin{array}{c}\text { \% } \mathrm{CH}_{2} \mathbf{O} \\
\text { Removed }\end{array}$ \\
\hline 5.5 & 100 & 0 & 43,600 & 3.8 & 99.9 \\
2.4 & 100 & 0 & 43,600 & 1.7 & 99.8 \\
1.5 & 100 & 0 & 43,600 & 1.0 & 98.4 \\
0.66 & 100 & 0 & 43,600 & 0.5 & 98.2 \\
\hline
\end{tabular}

\section{Conclusions}

The comprehensive understanding of the reaction conditions between formaldehyde and nitric acid at different conditions has enabled the discovery of the treatment conditions to achieve the complete mineralization of formaldehyde in synthetic and industrial wastewaters. The optimization of the variables, reaction time, concentration of $\mathrm{HNO}_{3}$ and temperature can be set using the proposed models, as a function of the industrial requirements. Furthermore, $\mathrm{NaNO}_{2}$ can be used as an option to accelerate the reaction, but it is not mandatory. The model at $85{ }^{\circ} \mathrm{C}$ fits quite well the behavior of the industrial formaldehyde wastewater; however, the models do not consider some of the behaviors observed for the reaction, such as the lower TOC removal at $100^{\circ} \mathrm{C}$.

The industrial wastewaters were successfully treated with nitric acid, enabling a complete removal of formaldehyde. It is also possible to treat highly concentrated streams without increasing the concentration of $\mathrm{HNO}_{3}$, which is important progress beyond minimizing the generation of both residual gas and nitrates in the treated water.

Author Contributions: Conceptualization, N.M., A.G.-E., C.N. and A.B. (Angeles Blanco); data curation, N.M., A.B. (Ana Balea), A.G.-E. and A.B. (Angeles Blanco); formal analysis, N.M., A.B. (Ana Balea) and J.T.; funding acquisition, A.B. (Angeles Blanco); investigation, N.M., A.B. (Ana Balea) and J.T.; methodology, N.M. and A.B. (Ana Balea); project administration, C.N. and A.B. (Angeles Blanco); supervision, N.M., A.G.-E., C.N. and A.B. (Angeles Blanco); validation, A.B. (Ana Balea); writing-original draft, N.M., A.B. (Ana Balea) and J.T.; writing-review \& editing, N.M., A.B. (Ana Balea), A.G.-E., C.N. and A.B. (Angeles Blanco). All authors have read and agreed to the published version of the manuscript. 
Funding: This research was funded by Science, Innovation and University Ministry of Spain grant number CTM2016-77948-R and Comunidad de Madrid in Spain grant number S2018/EMT-4459.

Acknowledgments: The authors would like to thank the Science, Innovation and University Ministry of Spain for the support of the project CTM2016-77948-R and Comunidad de Madrid in Spain for the support of the project S2018/EMT-4459.

Conflicts of Interest: The authors declare no conflict of interest.

\section{References}

1. Pereira, N.; Zaiat, M. Degradation of formaldehyde in anaerobic sequencing batch biofilm reactor (ASBBR). J. Hazard. Mater. 2009, 163, 777-782. [CrossRef]

2. Garrido, J.; Méndez, R.; Lema, J. Treatment of wastewaters from a formaldehyde-urea adhesives factory. Water Sci. Technol. 2000, 42, 293-300. [CrossRef]

3. Wieslander, G.; Norbäck, D.; Björnsson, E.; Janson, C.; Boman, G. Asthma and the indoor environment: The significance of emission of formaldehyde and volatile organic compounds from newly painted indoor surfaces. Int. Arch. Occup. Environ. Health 1996, 69, 115-124. [CrossRef] [PubMed]

4. Lippmann, M. Environmental Toxicants: Human Exposures and Their Health Effects, 3rd ed.; John Wiley \& Sons: Hoboken, NJ, USA, 2000; ISBN 978-0-471-79335-9.

5. Babu, B.R.; Parande, A.; Raghu, S.; Kumar, T.P. Textile technology. An Overview of Wastes Produced During Cotton Textile Processing and Effluent Treatment Methods. J. Cotton Sci. 1995, 11, 110-122.

6. Carlson, R.M.; Smith, M.C.; Nedorost, S.T. Diagnosis and treatment of dermatitis due to formaldehyde resins in clothing. Dermatitis 2004, 15, 169-175.

7. Costa, N.; Pereira, J.A.M.; Martins, J.M.; Ferra, J.; Cruz, P.; Magalhães, F.D.; Mendes, A.M.; Carvalho, L. Alternative to latent catalysts for curing UF resins used in the production of low formaldehyde emission wood-based panels. Int. J. Adhes. Adhes. 2012, 33, 56-60. [CrossRef]

8. Celik, F.E.; Lawrence, H.; Bell, A.T. Synthesis of precursors to ethylene glycol from formaldehyde and methyl formate catalyzed by heteropoly acids. J. Mol. Catal. A Chem. 2008, 288, 87-96. [CrossRef]

9. Guven, B.B.; Olaguer, E.P. Ambient formaldehyde source attribution in Houston during TexAQS II and TRAMP. Atmos. Environ. 2011, 45, 4272-4280. [CrossRef]

10. Moussavi, G.; Yazdanbakhsh, A.; Heidarizad, M. The removal of formaldehyde from concentrated synthetic wastewater using $\mathrm{O} 3 / \mathrm{MgO} / \mathrm{H} 2 \mathrm{O} 2$ process integrated with the biological treatment. J. Hazard. Mater. 2009, 171, 907-913. [CrossRef]

11. Yamazaki, T.; Tsugawa, W.; Sode, K. Biodegradation of formaldehyde by a formaldehyde-resistant bacterium isolated from seawater. Appl. Biochem. Biotech. 2001, 91, 213-217. [CrossRef]

12. Ezhilkumar, P.; Sivakumar, V.; Yogasri, A.; Thirumarimurugan, M. Biodegradation of formaldehyde using Bacillus subtilis in batch process. Int. J. Mater. Prod. Technol. 2017, 55, 296-307. [CrossRef]

13. De Oliveira, S.V.W.B.; Moraes, E.; Adorno, M.; Varesche, M.; Foresti, E.; Zaiat, M. Formaldehyde degradation in an anaerobic packed-bed bioreactor. Water Res. 2004, 38, 1685-1694. [CrossRef] [PubMed]

14. Cloteaux, A.; Gerardin, F.; Thomas, D.; Midoux, N.; André, J.-C. Fixed bed photocatalytic reactor for formaldehyde degradation: Experimental and modeling study. Chem. Eng. J. 2014, 249, 121-129. [CrossRef]

15. Gao, L.; Gan, W.; Xiao, S.; Zhan, X.; Li, J. Enhancement of photo-catalytic degradation of formaldehyde through loading anatase TiO2and silver nanoparticle films on wood substrates. RSC Adv. 2015, 5, 52985-52992. [CrossRef]

16. Ubolchonlakate, K.; Sikong, L.; Tontai, T. Formaldehyde degradation by photocatalytic Ag-doped TiO2 film of glass fiber roving. J. Nanosci. Nanotechnol. 2010, 10, 7522-7525. [CrossRef]

17. Hong, Q.; Sun, D.-Z.; Chi, G.-Q. Formaldehyde degradation by $\mathrm{UV} / \mathrm{TiO}_{2} / \mathrm{O}_{3}$ process using continuous flow mode. J. Environ. Sci. 2007, 19, 1136-1140.

18. Kajitvichyanukul, P.; Lu, M.-C.; Jamroensan, A. Formaldehyde degradation in the presence of methanol by photo-Fenton process. J. Environ. Manag. 2008, 86, 545-553. [CrossRef]

19. Moussavi, G.; Bagheri, A.; Khavanin, A. The investigation of degradation and mineralization of high concentrations of formaldehyde in an electro-Fenton process combined with the biodegradation. J. Hazard. Mater. 2012, 237, 147-152. [CrossRef] 
20. Parisheva, Z.; Nusheva, L.; Danova, N. Advanced oxidation of solutions containing formaldehyde part 1. Combined effect of ozone and hydrogen peroxide. Environ. Prot. Eng. 2003, 29, 5-14.

21. Healy, T.V. The Reaction of nitric acid with formaldehyde and with formic acid and its application to the removal of nitric acid from mixtures. J. Appl. Chem. 2007, 8, 553-561. [CrossRef]

22. Mishra, S.; Lawrence, F.; Sreenivasan, R.; Pandey, N.; Mallika, C.; Koganti, S.B.; Mudali, U.K. Development of a continuous homogeneous process for denitration by treatment with formaldehyde. J. Radioanal. Nucl. Chem. 2010, 285, 687-695. [CrossRef]

23. Kumar, S.V.; Nadkarni, M.N.; Mayankutty, P.C.; Pillai, N.S.; Shinde, S.S. Destruction of Nitric Acid in Purex Process Streams by Formaldehyde Treatment; Bhabha Atomic Research Centre: Trombay, Mumbai, 1974.

24. Horváth, M.; Lengyel, I.; Bazsa, G. Kinetics and mechanism of autocatalytic oxidation of formaldehyde by nitric acid. Int. J. Chem. Kinet. 1988, 20, 687-697. [CrossRef]

25. Sugaya, N.; Nakagawa, T.; Sakurai, K.; Morita, M.; Onodera, S. Analysis of Aldehydes in Water by Head Space-GC/MS. J. Health Sci. 2001, 47, 21-27. [CrossRef]

26. Álava, A.F.B.; Lucas, L.M.G.; Villamar, J.D.C.; Acebo, M.R.A.; Toala, T.O.M.; Parrales, T.M.M. Elementos de Química Básica; 3Ciencias: Alicante, Spain, 2018.

27. Liu, Y.; Wang, J.; Zheng, Y.; Wang, A. Adsorption of methylene blue by kapok fiber treated by sodium chlorite optimized with response surface methodology. Chem. Eng. J. 2012, 184, 248-255. [CrossRef]

(C) 2020 by the authors. Licensee MDPI, Basel, Switzerland. This article is an open access article distributed under the terms and conditions of the Creative Commons Attribution (CC BY) license (http://creativecommons.org/licenses/by/4.0/). 